\title{
Knowledge, Attitude and Awareness of Hepatitis B Vaccination in Patients Visiting Jinnah Postgraduate Medical Center, Karachi
}

\author{
Ali Mikdad Hassan ${ }^{1 *}$, Syeda Marium², Wabiha Zehra Jaffari ${ }^{3}$, Iqra Batool ${ }^{4}$ and Umme Rabab ${ }^{5}$ \\ ${ }^{1}$ Department of General Surgery, Jinnah Post Graduate Medical Center, Karachi, Pakistan \\ ${ }^{2}$ General Medicine, PNS Shifa, Karachi, Pakistan \\ ${ }^{3}$ Sindh Medical College, Jinnah Sindh Medical University, Karachi, Pakistan \\ ${ }^{4}$ Sindh Medical College, Jinnah Sindh Medical University, Karachi, Pakistan \\ ${ }^{5}$ Community Medicine, Jinnah Sindh Medical University, Karachi, Pakistan
}

\begin{abstract}
Background: Hepatitis B Virus (HBV) is a major health issue of the developing world, especially in Pakistan. Chronic Hepatitis B leads to an increased risk of liver cirrhosis and hepatocellular carcinoma and is a massive burden on the total health expenditure of the nation. However, in our country people lack knowledge regarding the HBV vaccine and its availability and have various other reasons for not getting vaccinated. The purpose of this research was to observe the attitude of patients visiting Jinnah Postgraduate Medical Center towards Hepatitis B vaccination as well as the reasons put forward by those who choose not to get vaccinated.

Objectives: The aim of this study was to evaluate the knowledge, attitudes and awareness regarding HBV vaccination in patients visiting Jinnah Postgraduate Medical Center.

Methodology: This is a cross sectional study that was conducted among patients who visited Jinnah Postgraduate Medical Center. 300 participants were included. The data collection method was a face-to-face interview. Non-probability convenience sampling technique was used to recruit patients. We used a self-structured, close-ended questionnaire based on the Urdu language consisting of a total of 40 questions. Prior written consent was taken. Data entry and data analysis were done by using SPSS Version 20.

Results: Out of 300 participants, $191(63.67 \%)$ of respondents had acquired matriculation or higher education while the rest were either just primary pass or illiterate. $216(72 \%)$ of the participants were aware that HBV is highly prevalent in Pakistan. $135(45 \%)$ considered alcohol and smoking as a cause of HBV. Only $43(14.3 \%)$ participants had knowledge regarding the standard dosing regimen of the vaccine. Participants had awareness about prevention. 250 (83.3\%) agreed that Hepatitis $\mathrm{B}$ vaccination is an effective method of prevention of Hepatitis B, while 59(19.6\%) thought that the vaccine itself can cause Hepatitis infection. 190(63.3\%) identified cost as a barrier for vaccination.

Conclusion: People in Pakistan don't have adequate knowledge about the mode of transmission of hepatitis, but they have good knowledge about preventive methods. The prevalent attitude is to not get vaccinated due to various reasons. Hence it is very important to spread awareness among people about HBV vaccination.
\end{abstract}

Keywords: Hepatitis $B$, vaccination awareness, knowledge, attitude.

\section{INTRODUCTION}

Hepatitis B Virus is a major global health problem specifically in developing countries where information regarding safety measures is not very common [1]. $\mathrm{HBV}$ is an oncogenic virus according to World Health Organization (WHO) [2]. It is a major cause of morbidity and mortality in developing as well as developed countries [1]. A study conducted in China showed that around 1 million people have Hepatitis B infection [3]. HBV can lead to acute hepatitis, chronic hepatitis, hepatocellular carcinoma, cirrhosis and death [4] with a prevalence of around $4-5 \%$ in the population of Karachi [5] and around $2.4 \%$ with a range $1.4-11.0 \%$ among the general population of Pakistan in 2008 [5]. Education and socioeconomic status also have a strong influence on the ratio of vaccinated population and the knowledge regarding HBV transmission [6]. HBV can be prevented

\footnotetext{
*Corresponding Author: Ali Mikdad Hassan, House Officer in General Surgery, Jinnah Post Graduate Medical Center, Karachi, Pakistan; Email: alimikdad123@gmail.com

Received: October 23, 2019; Revised: December 02, 2019; Accepted: December 20, 2019
} DOI: https://doi.org/10.37184/lnjpc.2707-3521.1.3 in the general population by providing them knowledge regarding the source of transmission of infection and by adopting preventive methods [7]. The main routes of HBV transmission include prenatal infection, blood transfusion, dialysis, invasive tests, use of contaminated syringes, surgery, razors and sexual contact [2]. There are two types of HBV vaccine: plasma-derived vaccine and recombinant DNA Hepatitis $B$ vaccine [8]. A single course of three doses of hepatitis $B$ vaccine is administered in different schedules such as at the $6^{\text {th }}, 10^{\text {th }}$ and $14^{\text {th }}$ week in infants [9] and in 0, 1 and 6 months in adults [10]. Hepatitis is a vaccine-preventable disease. Vaccination also prevents chronic liver disease. According to the WHO efficacy of the vaccine is outstanding with no side effects. Previous records show that more than $95 \%$ of the population was immune to hepatitis after vaccination [2]. As a result of vaccination, the prevalence of HBV infection is markedly decreasing which ultimately leads to a reduction in the burden of chronic liver disease and hepatocellular carcinoma [11]. Acceptance of HBV vaccination is an essential issue as a high risk of infection is due to high prevalence of virus carriers among the 
general population [12]. A study conducted in Islamabad found that only $59.4 \%$ of healthcare workers are fully vaccinated [13]. Although Hepatitis $B$ vaccination is the most effective method of preventing HBV infection [2], a study done among nursing students found that there was a $75 \%$ acceptance of HBV vaccination with only $37.2 \%$ having received all three doses according to schedule [12]. There are different reasons for not getting vaccinated: the main reasons being the high cost of vaccination, fear of injection, doubt over the efficacy of the vaccine, fear of side effects, lack of time, and belief that they are not at risk [14].The purpose of this research was to observe the attitude of patients visiting Jinnah Postgraduate Medical center towards vaccination as well as the reasons put forward by those who choose not to get vaccinated. Is a lack of awareness the real reason behind the low percentage of vaccination and high burden of infection?

\section{METHODOLOGY}

This was a cross-sectional study that was carried out on patients visiting "Jinnah Postgraduate Medical Centre, Karachi". The duration of the study was from Feb 2019 to June 2019. 300 participants were included in the study. Open-Epi sample size calculator was used for sample size calculation by taking prevalence for knowledge regarding vaccination of hepatitis $B$ as $22.5 \%$ [14], margin of error as $5 \%$ and a $95 \%$ confidence interval. The calculated sample was 268 . After inflating the sample size by $12 \%$ for missing data and nonrespondents, we included 300 patients in our study. Those visitors who had already been diagnosed with hepatitis B or treated in the past for hepatitis B or those who were already vaccinated for hepatitis B were not included in the study. Research purpose was explained to the participants and written inform consent was taken from all patients before enrolling them into study. Nonprobability convenience sampling technique was used to recruit study participants.

The study was conducted by using a self-structured closed-ended questionnaire consisting of a total of 40 questions based on the Urdu language. The questionnaire comprised of four components; the first component included demographic questions i.e. name, age, residence, marital status and education. The second component covered questions regarding knowledge of hepatitis B infection and HBV vaccine, as well as the risk factors and methods of prevention. The third component contained questions about the attitude of the general population towards HBV vaccination. The last part of questionnaire investigated the reasons for the lack of awareness of HBV vaccine. Face-to-face interview was conducted by primary investigator to collect the data. Data entry and data analysis were done by using SPSS Version 20.

\section{RESULTS}

A total of 300 patients visiting Jinnah Postgraduate Medical Center were enrolled into the study. All the participants were in the age group of 18-77 years with a mean age of 35.29 years. There were 144(48\%) male and $156(52 \%)$ female participants. Most of them were married ( $n=199,66.33 \%)$. In our study, 51(17.4\%) were uneducated, 51(17.4\%) had primary education, $50(17.06 \%)$ had completed their Matriculation, $59(20.1 \%)$ had completed Intermediate and $82(27.98 \%)$ had Bachelors' degree and $7(2.33 \%)$ didn't respond for this question.

\section{KNOWLEDGE OF HEPATITIS B}

Regarding knowledge of the transformation of hepatitis $B$ into hepatocellular carcinoma ( $\mathrm{HCC}$ ) and cirrhosis; $189(63 \%)$ participants believed that hepatitis B can lead to HCC and cirrhosis whereas $67(22.3 \%)$ did not have any knowledge about it. On being asked "Is HBV high prevalent disease in Pakistan?", 216(72\%) people replied in the affirmative. On inquiring about the causes of hepatitis B, 236(78.7\%) of our participants had prior knowledge that hepatitis $B$ is caused by unscreened blood transfusion, sharing used razors and syringes $(n=234,78 \%)$, dental procedures $(n=185,62.1 \%)$ and needle stick injury $(n=168,57.3 \%) .135(45 \%)$ participants believed that alcohol and smoking also cause hepatitis infection and 93(31.2\%) participants believed that mosquito bites can transmit infection (as given in Table 1). Among 299 participants, 128(42.8\%) believed that sharing daily use items or clothes, shaking hands, hugging or kissing infected individuals is a cause of the spread of hepatitis B infection among healthy individuals.

\section{PREVENTION FROM HEPATITIS}

Participants were asked about the methods of prevention of hepatitis B. $258(86 \%)$ said screening of blood while $263(88 \%)$ said use of sterilized syringes. $216(72.2 \%)$ agreed that their family members should get tested for hepatitis B. $250(83.3 \%)$ agreed that vaccination is an effective method of prevention from hepatitis $B$.

\section{KNOWLEDGE OF HBV VACCINE}

The results revealed that most participants $(n=194$, $65 \%$ ) were aware about the availability of hepatitis B vaccine and about the route of administration $(n=194$, $65 \%)$. However, the majority of them $(n=212,71.6 \%)$ were not aware about the dosing regimen of the vaccine.

\section{ADVERSE EFFECTS OF VACCINE}

$145(48.65 \%)$ of the participants included in this study thought that flu-like symptoms are the most common side effect of hepatitis $B$ vaccination. Participants were asked about the possibility of hepatitis $B$ vaccination causing hepatitis infection itself. 138(46.8\%) answered "no" compared to $59(20 \%)$ saying "yes" while the rest were unaware. 


\section{REASONS FOR NON-VACCINATION}

The participants were asked about their reasons for not getting vaccinated. Their reasons included: high price of vaccine $(n=190,63.3 \%)$, non-availability of vaccine $(n=146,48.7 \%)$, fear of side effects $(n=129,43 \%)$, fear of injection ( $n=118,39.3 \%)$. Around $201(67 \%)$ people believed that people avoid vaccination due to a lack of awareness.

\section{ATTITUDES TOWARDS GETTING VACCINATED}

264(88.3\%) participants agreed that people should get vaccinated against hepatitis B. $29(9.7 \%)$ people said that it can cause infertility among healthy people. 59(20\%) participants believed that vaccination can cause HBV infection among the healthy population. 107(35.7\%) participants believed that they would not get this infection in any way so there is no need for vaccination.

\section{DISCUSSION}

Pakistan is a developing country; the health sector faces many barriers in achieving its goals. Vaccination against hepatitis $B$ is a small measure that can have great effects, significantly reducing the burden of disease. However, despite being available all over the country, the burden of hepatitis B is increasing day by day. In our study, we assessed the knowledge, attitudes, and

Table. 1: Knowledge, Attitude and awareness of HBV AND HBV vaccine.

\section{Knowledge of Hepatitis $B$}

\begin{tabular}{|c|c|c|c|c|}
\hline S. No & Question & $\begin{array}{c}\text { Yes } \\
\text { Frequency (\%) }\end{array}$ & $\begin{array}{c}\text { No } \\
\text { Frequency (\%) }\end{array}$ & $\begin{array}{c}\text { Don't know } \\
\text { Frequency (\%) }\end{array}$ \\
\hline 1 & Can HBV lead to HCC and cirrhosis? & $189(63)$ & $44(14.7)$ & $67(22.3)$ \\
\hline 2 & HBV is high prevalent disease in Pakistan? & $216(72)$ & $31(10.3)$ & $53(17.7)$ \\
\hline 3 & HBV spread by sharing Razors and Syringes? & $234(78)$ & 19(6.3) & $47(15.7)$ \\
\hline 4 & By unscreened Blood Transfusion & $236(78.7)$ & $25(8.3)$ & $39(13)$ \\
\hline 5 & By Needle Stick Injury & $168(57.3)$ & $50(17.1)$ & $75(25.6)$ \\
\hline 6 & By Surgical or dental procedures & $185(62.1)$ & $35(11.7)$ & $78(26.2)$ \\
\hline 7 & By Tattooing on the skin & 148(49.3) & $65(21.7)$ & $87(29)$ \\
\hline 8 & By Sexual contact & $162(54.9)$ & $48(16.3)$ & $85(28.8)$ \\
\hline 9 & During Delivery from mother to fetus & $173(57.9)$ & $45(15.1)$ & $81(27.1)$ \\
\hline 10 & By Mosquito Biting & $93(31.2)$ & 119(39.93) & $86(28.9)$ \\
\hline 11 & $\begin{array}{l}\text { by sharing daily use items, Shaking Hands or Sharing Clothes and } \\
\text { Through Kissing and Hugging }\end{array}$ & $128(42.8)$ & $118(39.5)$ & $53(17.7)$ \\
\hline 12 & By Alcohol and smoking & $135(45)$ & $86(28.7)$ & $79(26.3)$ \\
\hline
\end{tabular}

Prevention from Hepatitis

\begin{tabular}{|c|c|c|c|c|}
\hline 1 & By proper screening of blood before transfusion & $258(86)$ & $3(1)$ & $39(13)$ \\
\hline 2 & Use Of sterilize syringes & $263(88)$ & $10(3.3)$ & $26(8.7)$ \\
\hline 3 & Screening of both partners for HBV & $216(72.2)$ & $23(7.7)$ & $60(20.1)$ \\
\hline 4 & By avoiding unnecessary skin picks & 185(61.9) & $39(13)$ & $75(25.1)$ \\
\hline 5 & By proper vaccination against HBV & $250(83.3)$ & $17(5.7)$ & $33(11.0)$ \\
\hline
\end{tabular}

Reasons for Non-Vaccination

\begin{tabular}{c|l|c|c|c}
\hline 1 & Vaccine is expensive & $190(63.3)$ & $60(20)$ & $50(16.7)$ \\
\hline 2 & People are afraid of injection & $118(39.3)$ & $123(41)$ & $59(19.7)$ \\
\hline 3 & Vaccine has no protective against the virus & $87(29)$ & $137(45.7)$ & $76(25.3)$ \\
\hline 4 & People are afraid of adverse effects & $129(43)$ & $108(36)$ & $63(21)$ \\
\hline 5 & People don't have time to vaccinate themselves & $84(28)$ & $140(46.7)$ & $76(25.3)$ \\
\hline 6 & They have a strong belief that they will never get infected & $107(35.7)$ & $128(42.7)$ & $65(21.7)$ \\
\hline 7 & Lack of awareness regarding vaccine & $201(67)$ & $52(17.3)$ & $47(15.7)$ \\
\hline 8 & Because of lack of vaccine availability & $146(48.7)$ & $51(17)$ & $103(34.3)$ \\
\hline Adverse & Effects of Vaccine & $156(52.3)$ & $39(13.1)$ & $103(34.6)$ \\
\hline 1 & Fever & $145(48.65)$ & $52(17.4)$ & $101(33.9)$ \\
\hline 2 & Flu like symptoms & $29(9.7)$ & $117(39)$ & $154(51.3)$ \\
\hline 3 & Infertility & $59(20)$ & $138(46.77)$ & $98(33.2)$ \\
\hline 4 & HBV infection because of vaccine & & & \multicolumn{2}{|c}{} \\
\hline
\end{tabular}


awareness of hepatitis B vaccination among people visiting Jinnah Postgraduate Medical Center. We reached the conclusion that many of our participants were aware that hepatitis $B$ is a highly prevalent disease in Pakistan. There is no doubt that Hepatitis B is the leading cause of chronic liver disease, but only $63 \%$ of our participants knew about this, even though $75.2 \%$ participants were aware of it in a previously conducted survey in Abbottabad [15]. Our study participants had a good knowledge regarding the transmission of hepatitis B. More than $70 \%$ people said that hepatitis B can be transmitted by sharing contaminated needles or razors and by unscreened blood transfusion (as seen in Table 1). In a KAP study done at an Obstetrics and Gynecology clinic in Hyderabad, only $33.8 \%$ of their participants knew that hepatitis can be transmitted by infected blood transfusion and $38.0 \%$ mentioned that contaminated needles was the cause [15]. People $(62.1 \%)$ were also aware that the use of unsterilized surgical and dental instruments was the major cause for the transfer of the virus, which is much lesser than a study done in Saudi Arabia where it was $94 \%$. This difference can be because of the fact that our participants didn't belong to the medical field [16]. According to a study conducted in France, $69.7 \%$ participants had knowledge about the transmission of hepatitis B through sexual contact but in our study only $55 \%$ agreed on this whereas $44 \%$ participants had no knowledge or did not agree that hepatitis B can be transmitted by sexual contact. Most of those who answered as such were educated. This may be because sex-related issues are not openly discussed in our society because of our cultural norms [17].

In our society, because of strong belief in myths and a lax attitude towards searching for authentic information, $44 \%$ of people thought that shaking hands, sharing clothes, or hugging can spread this disease from an infected person to a healthy person in comparison to a research that showed that $46 \%$ of university students also had the same views [7]. It was interesting to note that our respondents (88\%) had knowledge that hepatitis B can be prevented by vaccination. In a study that was done in Gujrat only $22.5 \%$ of people believed that vaccination is effective against hepatitis B [14]. More than $80 \%$ of our respondents knew the role of screening blood before transfusion in the prevention of disease and they also preferred using sterilized syringes. In a similar study carried out among students it was not more than $72 \%$ [7]. Approximately $2 / 3^{\text {rd }}$ of respondents knew that vaccination against hepatitis $B$ was available and other studies showed similar results [7]. We found amongst our participants who had never been vaccinated for hepatitis $B$ reasons which included: lack of knowledge (67\%), fear of side effects $(43 \%)$, expensive $(63.3 \%)$, unavailability in their area $(48.7 \%)$, ineffective (29\%) as shown in Table 1. Our findings were significantly different from a study conducted in the districts of India. The reasons found in their population for being unvaccinated were: lack of knowledge $(55.1 \%)$, high $\operatorname{cost}(0.3 \%)$, unavailability $(1.8 \%)$, less effective $(15.4 \%)$, dangerous side effects (3\%) [14]. Besides treating infected populations it is also important that the healthy population should be vaccinated to control the burden of disease in areas at risk and also educated about the importance of vaccination [18]. A lack of knowledge about vaccines and a poor attitude towards being vaccinated were the main reasons in our study for the vaccination status in our population being low. It was interesting to find out that $135(45 \%)$ of our participants believed that alcohol and smoking also cause hepatitis infection. 93(31.2\%) participants believed that mosquito bites can transmit infection. It is the need of the hour to remove these misconceptions from our society.

\section{STRENGTH}

Previously this type of research was conducted on medical students and nurses. This is the first time that this research is conducted in a public hospital setting in Karachi and includes patients.

\section{LIMITATIONS}

Our study only included visitors of Jinnah Postgraduate Medical Center Karachi which is a public hospital, thus it cannot represent the entire population of Karachi. The results could be different if this study was conducted in a private setting.

\section{CONCLUSION}

Most people knew that hepatitis B infection is very common in Pakistan and has lethal consequences but had little knowledge about the transmission of disease and the availability of vaccination. However, they had good knowledge of preventive methods yet had a poor attitude towards self-vaccination. Efforts should be made to spread awareness about the importance of vaccination so that the burden of disease can be reduced.

\section{CONFLICT OF INTEREST}

The authors declare that they have no affiliations with or involvement in any organization or entity with any financial interest (such as honoraria; educational grants; participation in speakers' bureaus; membership, employment, consultancies, stock ownership, or other equity interest; and expert testimony or patentlicensing arrangements), or non-financial interest (such as personal or professional relationships, affiliations, knowledge or beliefs) in the subject matter or materials discussed in this manuscript.

\section{ACKNOWLEDGEMENT}

Foremost, I would like to express my sincere gratitude to my research advisor Dr. Umm-e-Rabab Naqvi for her continuous support, motivation and guidance. Without her guidance it was not possible for me to complete this research. 
Besides my advisor, I would like to appreciate my team members for their hard work and sincere efforts in various parts of this research as listed below:

- "Dr. Syeda Marium" for designing this research and collecting data.

- "Wabiha Zehra Jafri" for data collection and report writing.

- "Iqra Batool" for data collection and report writing.

- Myself (Dr. Ali Mikdad) for designing this research, analysing data and formatting results.

\section{REFERENCES}

1. Zhang $C$, Zhong $Y$, Guo L. Strategies to prevent hepatitis B virus infection in China: immunization, screening, and standard medical practices. Biosci Trends 2013; 7(1): 7-12.

2. Hepatitis B. World Health Organization, 2019. Available at: https:// www.who.int/news-room/fact-sheets/detail/hepatitis-b.

3. Hamdiui N, Stein ML, Timen A, et al. Hepatitis B in MoroccanDutch: a quantitative study into determinants of screening participation. BMC Med 2018; 16(1): 47.

4. Hakim ST, Kazmi SU, Bagasra O. Seroprevalence of hepatitis $B$ and $C$ genotypes among young apparently healthy females of Karachi, Pakistan. Libyan J Med 2008; 3(2): 66-70.

5. Ali SA, Donahue RM, Qureshi H, Vermund SH. Hepatitis B and hepatitis $C$ in Pakistan: prevalence and risk factors. Int $\mathrm{J}$ Infect Dis 2009; 13(1): 9-19.

6. Zhu D, Guo N, Wang J, et al. Socioeconomic inequality in hepatitis $B$ vaccination of rural adults in China. Hum Vaccin Immunother 2018; 14(2): 464-70.

7. Ghouri A, Aslam SO, lqbal YA, Shah AA. Knowledge and awareness of hepatitis $B$ among students of a public sector university. Isra Med J Pak 2015; 7(2): 95-100.
8. Baclic O, Choudhri Y, Henry B, Ismail S, Morton V. Update on the recommended use of hepatitis B vaccine. Government of Canada, 2017. Available at: https://www.canada.ca/en/public-health/ services/publications/healthy-living/update-recommended-usehepatitis-b-vaccine.html.

9. Andy SY, Cheung RC, Keeffe EB. Hepatitis B vaccines. Infect Dis Clin 2006; 20(1): 27-45.

10. Vaccines. World Health Organization, 2015. Available at: https:// www.who.int/topics/vaccines/en/.

11. Mengal HU, Howteerakul N, Suwannapong N, Rajatanun T. Factors relating to acceptance of hepatitis $B$ virus vaccination by nursing students in a tertiary hospital. Pak J Health Popul Nutr 2008; 26(1): 46-53.

12. Nasir K KK, Kadri WM, Salim S, Tufail K, Sheikh HZ, Ali SA. Hepatitis $B$ vaccination among health care workers and students of a medical college. J Pak Med Assoc 2000; 50(7): 1-8.

13. Abidi TF, Ahsan SJ, Fatima N. Hepatitis B vaccination coverage and immunization status among health care workers in Punjab and Islamabad, Pakistan. South Asian J Emerg Med 2018; 1(1): 16-21.

14. Yasobant S, Trivedi P, Saxena D, Puwar T, Vora K, Patel M. Knowledge of hepatitis $B$ among healthy population: a communitybased survey from two districts of Gujarat, India. J Family Med Prim Care 2017; 6(3): 589.

15. Haider G, Haider A. Awareness of women regarding hepatitis B. J Ayub Med Coll Abbottabad 2008; 20(4): 141-4.

16. Al-Shamiri HM, AIShalawi FE, AlJumah TM, AlHarthi MM, AlAli EM, AlHarthi HM. Knowledge, attitude and practice of hepatitis B virus infection among dental students and interns in Saudi Arabia. J Clin Exp Dent 2018; 10(1): e54.

17. Brouard C, Gautier A, Saboni L, Jestin C, Semaille C, Beltzer N Hepatitis B knowledge, perceptions and practices in the French general population: the room for improvement. BMC Public Health 2013; 13(1): 576.

18. Okonkwo UC, Ngim OE, Osim $\mathrm{H}$, et al. Knowledge of hepatitis $\mathrm{B}$ virus infection among traders. Nigerian J Clin Pract 2017; 20(4): 415-20. 